\title{
BOURDIEU, GRAMSCI E FOUCAULT: NOTAS PARA ANÁLISE DE FONTES IMPRENSAS PARA HISTÓRIA DA EDUCAÇÃO A PARTIR DA HISTÓRIA INTELECTUAL
}

\author{
Eliezer Felix de Souza* \\ lattes.cnpq.br/4870668302148616
}

\begin{abstract}
Resumo: Nas pesquisas que temos realizado na história da educação, nosso estudo volta-se para a perspectiva abordada pela História Intelectual. Essa perspectiva, a partir do diálogo com vários autores, tem buscado estudar o funcionamento de uma sociedade intelectual e sua relação com o campo, bem como as visões de mundo e a maneira de pensar dos intelectuais. Nesse sentido, o objetivo central deste texto é explicitar a experiência relacionada com fontes impressas para história e história da educação mobilizando discussões teóricas conduzidas pelos estudos de Gramsci, Bourdieu e Foucault. De forma geral buscamos instigar o debate a partir de alguns conceitos desses autores que possibilite utilizar as fontes impressas para a história e história da educação visando contribuir com os pesquisadores que têm adotado a imprensa enquanto objeto, mas, sobretudo fonte para pesquisas histórico-educacional.
\end{abstract}

Palavras-chave: Fontes imprensas; História intelectual da educação; Discussões teóricas.

\section{BOURDIEU, GRAMSCI AND FOUCAULT: NOTES FOR ANALYSIS OF PRINT SOURCES FOR EDUCATION HISTORY FROM OF INTELLECTUAL HISTORY}

\begin{abstract}
In the research we have done, our study turns to the perspective approached by Intellectual History. This perspective, from the dialogue with several authors, has sought to study the functioning of an intellectual society and its relation to the field, as well as the world views and the way of thinking of the intellectuals. In this sense, the central objective of this text is to explain the experience related to printed sources for history and history of education by mobilizing theoreticalmethodological discussions conducted by Gramsci, Bourdieu and Foucault. In a general way, we seek to instigate the debate based on some concepts of these authors that makes it possible to use printed sources for the history and history of education, in
\end{abstract}

\footnotetext{
* Doutor em Educação pela Universidade Estadual de Ponta Grossa, UEPG (Brasil). Contato: eliezer.felix@hotmail.com.
} 
order to contribute to the researchers who have adopted the press as an object, but above all a source for historical educational research.

Keywords: Press sources; Intellectual history of education; Theoretical discussions.

\section{Introdução}

Ao longo de alguns anos temos pesquisado a história e história intelectual da educação, utilizando como fonte a imprensa periódica (jornais e revistas). Entre as fontes para a história da educação, destacamos que a imprensa tem sido um objeto considerável. Por isso, utilizar-se de um jornal ou revista como fonte para pesquisa em historia da educação, significa expandir os debates, uma vez que o campo jornalístico pode ser entendido como arena do debate intelectual. Neste aspecto, a imprensa pauta-se pela disputa de interesses em jogos, estabelecendo visões de mundo e multifacetado as opiniões. Neste interim, buscamos, a partir das iniciativas em torno da imprensa como fonte de pesquisa, refletir sobre as relações e interações sociais e de poder que ela estabelece uma vez que aborda temáticas variadas.

Diante dos vários assuntos que a imprensa apresenta não tem como deixar de reconhecer o impacto dos jornais e a importância das mídias no processo de interação e informação das pessoas. Por isso a necessidade de investigar a sua importância na constituição dos aspectos mais amplos de sociabilidade e de subjetividade. Esse aspecto compreende o processo educativo incorporando as novas técnicas e, mais do que isso, promover a capacidade crítica dos textos, imagens e das transmissões feitas pela mídia, bem como pensar a necessidade da utilização dos jornais impressos como essenciais nas pesquisas históricas. Nesse aspecto, um dos pontos importantes, refere-se a aos cuidados dos impressos como fontes históricas. 
Um relato interessante sobre a preservação dos jornais como fonte no Brasil pode ser observado em Veiga (2007, p. 141). A autora faz referência ao texto "Retrato do Brasil" que informa que no ano de 1977, quando deram início à pesquisa do fascículo "Nosso Século", a Abril Cultural, os jornalistas Vladimir Sachetta e Paulo Cesar Azevedo constaram, na prática, as dificuldades de se estudar a história do país e, sobretudo, o desleixo com a preservação da chamada memória nacional. Em três anos de pesquisa descobriram que os arquivos do jornal Última Hora, fundado pelo jornalista Samuel Wainer em 1951, não mais existiam. Ainda no relato observa-se um comunicado em relação ao jornal Diário Carioca, que, vendido em 1971, seus arquivos foram colocados na rua e depois incinerados. Com o Correio da Manhã, também no Rio, quase aconteceu a mesma coisa. Os arquivos foram salvos por acaso, sendo os móveis de aço da empresa leiloados e arrematados pelo empresário Fernando Gasparian, dono do ex-semanário Opinião e da editora Paz e Terra. Dentro dos móveis como brinde, estava todo o material fotográfico do jornal. Depois de tentar vendê-lo a empresas editoriais, sem sucesso, o empresário dou o acervo ao Arquivo Nacional, onde em 1984 ainda estava a espera de organização.

Se a falta de zelo na preservação das fontes impressas é evidente, pesquisar a história brasileira na atualidade, a partir da imprensa e grande mídia, ficou extremamente difícil. Ao longo do século XX observamos transformações que contagiaram praticamente todos os setores sociais de comunicação. Entre eles, a difusão na circulação da informação por uma variedade enorme de agências informativas, que compreende, além dos grandes jornais e revistas, canais de televisão e portais na internet. Diante desse quadro é preciso que os pesquisadores das fontes impressas reformulem a problemática em torno do individual, na sua vivência íntima ou mesmo privada, buscando criar uma consciência coletiva. Isso porque ao converter anseios pessoais ou mesmo coletivos em conversação pública, os debates e textos opinativos mobilizados por jornalistas, políticos e comentadores midiáticos impõe a problematização dos problemas sociais, numa seleção, que hora prioriza os fatos mais espetacula- 
res, hora reflete temáticas de impactos na transformação social, envolvendo debates que repercutem assuntos de interesses variados.

Em nossas pesquisas, iniciadas em 2002, e prosseguida até aqui, nos utilizamos das fontes imprensas para pesquisa em história e educação. Nossa experiência parte do pressuposto que o trabalho jornalístico se dá por um processo de interação, onde as revistas impressas servem como um termômetro temático, uma vez que delas partem os assuntos e temáticas que, em hipótese, devem ser investigados com maior propriedade. Por isso com frequência os jornalistas da TV, dos jornais impressos e da rádio, falam e referenciam o que está nas revistas. Sendo assim, nossos estudos comprovam que a maioria das visões jornalísticas, com raras exceções, apresentam um processo de constituição e representação social dos acontecimentos que vão praticamente na mesma direção. Desse modo, quando se lê tudo o que foi escrito sobre o movimento carismático, ou sobre o debate educativo na impressa, ou ainda sobre a restauração e federalização da universidade do Paraná (temáticas que apresentamos a seguir), o que se observa são assuntos ou reportagens sobre o mesmo conteúdo.

Essa assertiva permite-nos entendermos que a mídia atua sobre os momentos que ela considera como mais importantes e a partir disso cria uma representação coletiva. O que se confronta muitas vezes são tendências editoriais. É neste aspecto que podemos trabalhar com o afastamento das realidades, onde, no seu intento de argumentar sobre os interesses diversos, em termos políticos, econômicos, sociais, ou mesmo culturais, os jornalistas apelam para interpretações e prejulgamentos com distorções que chegam deformadas na opinião pública. O papel do pesquisador é cruzar as várias versões informativas e escrever a história a partir do que as fontes apresentam. Esse aspecto só será possível num dialogo historiográfico e metodológico, como por exemplo, mobilizados pela abordagem da história intelectual que dão uma contribuição significativa para o uso das fontes impressas para história da educação.

No que se refere a história intelectual dialogamos com Helenice Rodrigues da Silva. De acordo com esta pesquisadora (2003), a noção de intelectual tem um caráter polissêmico e com constantes modificações, 
sempre levando em consideração os fatores históricos e sociais e que diferentes épocas fornecem modelos distintos de representação. Segundo ela "[...] domínio novo e mal definido, a história intelectual transformouse, nas últimas décadas, em estimulante objeto de investigação" (SILVA, 2003, p. 15). Em seu entendimento,

[...] a história intelectual parece visar, essencialmente, a dois eixos de análise: por um lado, o funcionamento de uma sociedade intelectual (o conceito de "campo" de Bourdieu, ou seja, suas práticas, suas estratégias, seus habitus; por outro lado as características de um momento histórico e conjuntural [...] que impõe visões de mundo, esquemas de percepção e apreciação, enfim, modalidades específicas de pensar e de agir por parte dos intelectuais. (SILVA, 2002, p. 12, grifos da autora).

Das indicações de Rodrigues que entre outras considerações aponta que a História Intelectual possibilita diferentes enfoques, como, por exemplo, o contexto de produção de ideias, análise da trajetória do indivíduo, as relações sociais estabelecidas com seus pares, as visões de mundo e os esquemas de pensamento de um determinado meio intelectual, buscamos interlocução com os apontamentos teóricos de Gramsci, Bourdieu e Foucault para análise de fontes impressas.

\section{Gramsci: os intelectuais como organizadores da cultura e o papel do jornalismo na sociedade moderna}

Das discussões promovidas em torno da história intelectual que utilizamos em nossas pesquisas, Gramsci tem um papel importante. No horizonte teórico da história intelectual um dos debates se refere ao conceito de intelectual discutido por ele. Em suas análises, esse pensador distingue a intelectualidade tradicional, considerada classe ou comunidade à parte, e os grupos que as classes produzem organicamente a partir das suas relações. Essas novas classes exercem funções predominantemente intelectuais e fazem parte de instituições ligadas à atividade cultural. $\mathrm{O}$ elemento fundamental oriundo das reflexões de Gramsci consiste em re- 
conhecer que os intelectuais não constituem camadas externas às lutas políticas, sociais e culturais. Ao contrário, o intelectual se caracteriza pelo imiscuir-se nas diferentes esferas da vida societária. E uma dessas esferas é o jornalismo que, no mundo moderno, passou a exercer um espaço profícuo no processo de constituição de novos modos de pensar, de agir, de sentir e de ser. É necessário entender as reflexões sobre a função social dos intelectuais à luz das ideias de Gramsci. A preocupação historicista desse pensador é traduzida com o postulado de que não existe nenhum a priori de formação e/ou posição institucional para definir o intelectual. Para ele

\begin{abstract}
Não há atividade humana da qual se possa excluir toda intervenção intelectual, não se pode separar o homo faber do homo sapiens. Em suma, todo o homem é intelectual, fora de sua profissão, desenvolve uma atividade intelectual qualquer, ou seja, é um "filosofo", um artista, um homem de gosto, participa de uma concepção de mundo, possuí uma linha consciente de conduta moral, contribui assim para manter ou para modificar uma concepção de mundo, isto é, para promover novas maneiras de pensar. (GRAMSCI, 2006, p. 52-53).
\end{abstract}

Na concepção de Gramsci, os intelectuais se distinguem em dois níveis. De um lado a intelectualidade tradicional; do outro os grupos pensantes que as classes produzem. Gramsci entende os intelectuais orgânicos não apenas como produtores teóricos, mas principalmente como aqueles que difundem a concepção de mundo se envolvendo na vida prática dos grupos sociais. Em nossa análise não exploramos o adjetivo orgânico, pois não houve a pretensão de localizar entre os integrantes do jornal pesquisado (Diário dos Campos) suas relações com as classes sociais. O que é relevante da discussão de Gramsci é a atribuição dada aos intelectuais, qual seja: de organizadores de visões de mundo e mobilizadores dos indivíduos em prol de projetos políticos, sociais e culturais. Com relação ao conceito desta, Gramsci o compreende em duas direções. Segundo Carlos Eduardo Vieira (1999, p. 193), "de um lado significa o modo de viver, de pensar, de agir e de sentir por parte de um grupo ou de uma civilização; de outro, cultura é entendida como projeto de formação do indivíduo, como ideal educativo a ser transmitido às novas gerações”. 
Neste contexto de transformação cultural e intelectual, Gramsci (2006, p. 32) chama a atenção para as "instituições ligadas a atividade cultural". Para o autor, essas características se definem a partir de

Método e problemas de método do trabalho intelectual e cultural seja criativo ou divulgativo. Escola, academia, círculos de diferentes tipos, tais como instituições de elaboração colegiada da vida cultural. Revistas e jornais como meios para organizar e difundir determinados tipos de cultura. (GRAMSCI, 2006, p. 19).

Gramsci nos chama a atenção nesta passagem para o surgimento dos novos intelectuais. A estes, ampliados em longa escala, cabe o papel de organizadores da cultura e da formação humana. Segundo Gramsci, "o modo de ser do novo intelectual não pode mais consistir na eloquência, motor exterior e momentâneo dos afetos e das paixões, mas uma inserção ativa na vida prática, como construtor, organizador, "persuasor permanente, já que não apenas orador puro" (GRAMSCI, 2006, p. 19). Compartilhando as ideias de Gramsci, mas num recuo cronológico considerável, Norberto Bobbio contextualiza as atuações desse novo intelectual:

Após a invenção da imprensa, a figura típica do intelectual passa a ser o escritor, o autor de livros, de libelos, e depois de artigos para revistas e jornais, de volantes de manifestos, de cartas públicas, ao qual corresponde a contrafigura do escrevinhador (pennivendolo) ou do escrevedor (pennaiolo). [...] alargou-se enormemente o espaço e, portanto a influência da palavra dita (sem, porém que diminua a da palavra escrita), a característica principal da moderna camada dos intelectuais está associada à formação de uma sempre mais vasta opinião pública por intermédio da imprensa, tanto que o fenômeno da opinião pública e o fenômeno da camada dos intelectuais no sentido moderno da palavra nascem simultaneamente, e acrescida a influência destes avalia-se habitualmente pela formação de um público sempre mais amplo em condições de exprimir e fazer valer a própria opinião. (BOBBIO, 1997, p. 121).

No entendimento de Carlos Eduardo Vieira (2001, p. 55), "investigamos os intelectuais porque consideramos que as suas ideias e a as suas trajetórias são testemunhos privilegiados dos diversos projetos formativos que demarcam as disputas em torno da direção dos processos de 
formação de novas gerações”. Na esteira dessa afirmação é possível reiterar que são os intelectuais os principais responsáveis por traduzir em termos teóricos e, sobretudo, nos marcos de um plano de ação política, os objetivos almejados pelos diferentes grupos e classes sociais que disputam os espaços formativos na sociedade; isto é, as funções de domínio e de direção cultural.

Partindo desse pressuposto na pesquisa intitulada Intelectuais, Modernidade e discurso educativo no jornal (SOUZA, 2010) adotamos como fonte única os jornais O Progresso e Diário dos Campos. O objetivo principal foi analisar a recepção dos debates nacionais sobre educação no discurso dos intelectuais dos periódicos citados no período compreendido entre 1907 e 1928. Nesse período, atuaram no jornal Jacob Holzmann, Hugo de Borja Reis e José Cadilhe que, além de editores foram proprietários do referido periódico. Com exceção de Hugo Reis, a maioria dos artigos não foram assinados por esses intelectuais. Entretanto, enquanto editores do jornal, defendemos a hipótese de que tiveram autonomia para autorizar ou impedir a circulação desses discursos. Desse espaço cultural os intelectuais discutiram os problemas da sociedade e da educação brasileira, paranaense e ponta-grossense.

À luz dos conceitos de cultura e intelectuais postulados por Gramsci defendemos que tais jornalistas dialogaram com as ideias educativas que circulavam na imprensa nacional, apropriando-se de muitos aspectos para trazer à baila problemas específicos da educação paranaense. De Gramsci defendemos os jornalistas como intelectuais organizadores da cultura e visões de mundo. Os apontamentos teóricos de Gramsci nos levaram a uma segunda indagação: Como se da o processo de produção cultural? Generalizamos o texto jornalístico como um conjunto de interação social. A explicação deste aspecto foi especificada a partir das explicações de Bakhtin (2002) que destaca a importância da interação verbal social entre os discursos produzidos pela imprensa, local, e as abordagens veiculadas pela imprensa a nível nacional e mesmo internacional. Foi possível a partir dessa orientação perceber que os jornalistas de Ponta Grossa estavam conectados com todo um debate mais amplo em torno 
do discurso educativo nacional e internacional do qual criavam certo sentido para debater a própria questão da educação local.

Em síntese, os intelectuais do jornal pesquisado atribuíram relevância à causa educacional. Ao promover a discussão sobre os problemas societários elegeram a questão educacional como temática relevante. $\mathrm{O}$ discurso educacional presente neste periódico estava sintonizado ao debate que circulava nas principais cidades brasileiras. A rigor, enunciava os problemas do analfabetismo, da educação feminina, da profissionalização da mulher (professora/educadora), da higienização, das reformas educativas, da formação do professor, da educação republicana (pública, laica e gratuita), da educação primária, da construção de prédios próprios para ensinar (grupos escolares) e da escola moderna (métodos práticos e inovadores). Com isso destacamos como fundamental os estudos de Gramsci para analise de fontes impressas para a história da educação.

\section{O intelectual em Bourdieu e o conceito de campo para pesquisas com fontes impressas}

Do debate estabelecido pela História Intelectual buscamos interlocução com Bourdieu. Quando olhamos a obra desse autor numa visão de conjunto percebemos o intelectual como agente preocupado em produzir conhecimentos acadêmicos, garantindo a autonomia do campo de produção cultural, mas também atento ao compromisso público e à responsabilidade ética de usar o conhecimento técnico para conhecer o homem e a sua relação no espaço. Em uma perspectiva mais ampla, o intelectual coletivo, que busca a partir da produção do conhecimento, conhecer as realidades sociais, na qual a contribuição desse autor leva em consideração as relações dos agentes sociais no interior dos vários campos. Para o sociólogo,

Os campos se apresentam à apreensão sincrônica como espaços estruturados de posições (ou de postos) cujas propriedades dependem das posições nestes espaços, podendo ser analisadas 
independentemente das características de seus ocupantes (em parte determinadas por elas). (BOURDIEU, 2003, p. 119-120).

Por isso, em Bourdieu, "[...] cada vez que se estuda um novo campo, seja o campo da filologia no século XIX, da moda atual ou da religião da Idade Média, descobrem-se propriedades específicas, próprias a um campo particular [...]" (BOURDIEU, 2003, p. 119-120). Sobre essas especificidades, Bourdieu chama atenção para as variáveis nacionais, tais como a luta entre os pretendentes e os dominantes que assumem formas diferentes. Por isso, para Bourdieu "[...] em cada campo se encontrará uma luta, [...] entre o novo que está entrando e que tenta forçar o direito de entrada e o dominante que tenta defender o monopólio e excluir a concorrência" (BOURDIEU, 2003, p. 119-120).

Pelas definições de Bourdieu, um campo se estrutura em uma relação de força entre agentes, instituições, etc. Conforme Cristina Carta Cardoso Medeiros (2007, p. 52), “[...] substituto da noção de sociedade, o conceito de campo foi formulado para lembrar que o verdadeiro objeto e centro das operações de pesquisa em Ciências Sociais, não é o indivíduo, mas a rede de relações das quais esse indivíduo participa”. No entendimento da autora, "[...] um campo pode ser definido como uma rede, ou como uma configuração de relações objetivas entre posições, [...] que impõem a seus ocupantes (agentes ou instituições) por sua situação atual e potencial na estrutura da distribuição de diferentes espécies de poder e capital" (MEDEIROS, 2007, p. 53). Ou seja, um campo funciona como um campo magnético capaz de impor aos objetos e aos agentes que nele penetram uma gravidade específica, funcionando como "campos de força”. Logo, o intelectual em Bourdieu, esta relacionado com a disputa por espaços dentro de vários campos.

A partir das orientações de Bourdieu analisamos a dimensão da "campanha" promovida pela imprensa paranaense em torno da temática restauração e federalização da Universidade do Paraná, que, de certa forma, evidencia a configuração político-acadêmica na Universidade do Paraná. Por isso, apesar da complexidade da teoria de Bourdieu fazemos aqui um recorte no campo do jornalismo. Conforme Bourdieu (1997, p. 25, grifo do autor), na obra Sobre a televisão, “[...] os jornalistas têm 
'óculos' especiais a partir dos quais veem certas coisas e não outras; e veem de certa maneira as coisas que veem”. Essa assertiva de Bourdieu dáse porque "[...] eles operam uma seleção e uma construção do que é selecionado" (BOURDIEU, 1997, p. 25). E essa seleção, por sua vez, na avaliação de Bourdieu, "[...] é a busca do sensacional, do espetacular" (BOURDIEU, 1997, p. 25). Interessando-se pelo excepcional a partir do ponto de vista deles:

Impõe a "perseguição do furo" eles estão "para fazer ver alguma coisa, está-se disposto a quase tudo e como se copia mutuamente visando a deixar os outros para trás, a fazer antes dos outros, acabam-se por fazerem tudo a mesma coisa, e a busca da exclusividade, que em outros campos, produz a originalidade, a singularidade, resulta aqui na uniformização e na banalização”. (BOURDIEU, 1997, p. 27, grifos do autor).

Nesse sentido, Bourdieu define o campo do jornalismo como sendo "[...] um microcosmo que tem leis próprias e que é definido por sua posição no mundo global e pelas repulsões que sofre de outros microcosmos" (BOURDIEU, 1997, p. 55). Por isso, “[...] dizer que ele é autônomo, que tem sua própria lei, significa dizer que o que nele se passa não poder ser compreendido de maneira direta a partir de fatores externos" (BOURDIEU, 1997, p. 55). Para ele, "[...] o campo jornalístico age, enquanto campo, sobre os outros campos. Em outras palavras, um campo, ele próprio cada vez mais dominado pela lógica comercial, impõe cada vez mais limitações aos outros universos" (BOURDIEU, 1997, p. 81).

Dos jornais analisados, além da informação, foi possível observar a discussão sobre a temática, trazendo professores da Universidade e intelectuais paranaenses para se posicionarem sobre o assunto. No que se refere a restauração, a imprensa paranaense começou destacando a nomeação de Brasil Pinheiro Machado para interventor do Estado. Em matéria que circulou na Gazeta do Povo em 16 fevereiro de 1946, o periódico anunciou $O$ novo interventor no Paraná. No início do texto, ele comentou que o "[...] excelentíssimo presidente da República tendo vários ilustres nomes no nosso Estado [...] escolhe, para o alto e honroso mandato, o Dr. Brasil Pinheiro Machado”. Foi no Governo de Brasil Pinheiro que o 
debate em torno da restauração das faculdades do Paraná tomou uma dimensão significativa na imprensa paranaense. Professor da Faculdade de Filosofia, ele priorizou em seu governo a escolha do secretariado predominantemente composta por professores da Universidade. Entre os nomes escolhidos estavam o de Homero Batista de Barros para a pasta da Educação e Flavio Suplicy de Lacerda a de Obras Públicas. (GAZETA DO POVO, 27 fev. 1946).

A imprensa paranaense deu ampla cobertura ao momento que antecedeu à restauração da Universidade do Paraná, publicando em suas páginas as falas de professores, de políticos e de estudantes e fechando a concretização vitoriosa com grande destaque. Dentre as personalidades os periódicos paranaenses destacam os nomes de Victor Ferreira do Amaral, Brasil Pinheiro Machado, Algacyr Munhoz Maeder, Pedro Calmon e, sobretudo, João Ribeiro de Macedo Filho. Na campanha pela restauração, observa-se uma aproximação muito grande entre o campo político e o campo acadêmico, chegando, muitas vezes, a confundirem-se os dois espaços sociais, uma vez que professores da Universidade, ao mesmo tempo, ocupavam cargos políticos em nível Estadual e Federal. Brasil Pinheiro Machado (Interventor no momento da restauração), Erasto Gaertner e Bento Munhoz da Rocha (deputados), Flávio Suplicy de Lacerda e Homero de Barros (Secretários de Estado) são exemplos dessa situação. Esses políticos-docentes uniram-se aos demais professores para debater o assunto com autoridades nacionais, a exemplo dos Ministros Souza Campos, Clemente Mariani e do Presidente Dutra. Com a concretização da luta e a consequente restauração da Universidade, a imprensa paranaense detalhou e continuou distribuindo elogios aos signatários da campanha.

Juntos desses nomes, Flávio Suplicy de Lacerda passou a ter visibilidade no campo do poder universitário. A chegada dele a esse campo só pode ser compreendida a partir de sua relação com o campo político. Para esse entendimento, é preciso que façamos uma breve reflexão. Em 1930, quando ingressou no campo acadêmico, filiou-se ao Círculo de Estudos Bandeirantes. Esse Círculo reuniu um grupo de intelectuais que, em 1938, fundou a Faculdade de Filosofia Ciências e Letras da Universi- 
dade do Paraná. Da Faculdade de Engenharia Flávio Suplicy angariou boas relações com Plínio Tourinho, além de participar de um grupo influenciado por Moreira Garcez e Arthur Franco. Da Faculdade de Filosofia, entre outros, Flávio Suplicy ganhou reconhecimento de Brasil Pinheiro Machado, filiado ao PSD, mesmo partido dele e que tinha uma boa relação com Manoel Ribas, afilhado político de Vargas. Do mesmo modo, Moysés Lupion, Governador do Paraná e o Presidente Eurico Gaspar Dutra eram filiados ao PSD. Portanto, o entendimento dessa configuração política, atrelada a Flávio Suplicy, permite compreender os passos iniciais de sua investida no campo de poder universitário e, sobretudo, o apoio na campanha de federalização.

Depois de investido no poder universitário, Flávio Suplicy usou de estratégias para se manter no campo do poder. Umas das estratégias foi a Campanha pela federalização da Universidade. Essa campanha recebeu na imprensa paranaense o discurso de "um momentoso assunto" e explicita a relação entre o campo acadêmico e o campo político. A repercussão dessa campanha pode ser percebida em matéria que circulou no dia 30 de dezembro na Gazeta do Povo:

[...] está já no conhecimento público o conteúdo da concisa e, não obstante, vibrante conclamação do Magnífico Reitor da Universidade do Paraná, o distinto professor Flávio Lacerda a professores, universitários, ex-alunos, entidades culturais e ao povo para se unirem àquela grande instituição para o esforço comum de conseguir a reparação de grave injustiça contra nós, ao excluí-la o Congresso dos benefícios da federalização. (GAZETA DO POVO, 30 dez. 1949).

Para o jornal, o anúncio da federalização das Universidades com a "inclusão de todas as escolas do país" no projeto de federalização "[...] posta a margem apenas a Universidade do Paraná [...] chocou vivamente a consciência universitária de nossa terra" (GAZETA DO POVO, $30 \mathrm{dez}$. 1949). A consequência dessa exclusão "[...] provocou imediata, enérgica, embora serena reação tão oportuna, tão bela, tão eficientemente manifestada por sua Magnificência, o Sr. Reitor, num dos momentos mais solenes e empolgantes da vida daquele esplêndido Instituto de ensino superior" (GAZETA DO POVO, 30 dez. 1949). Neste sentido, enfatizando que 
a Gazeta do Povo sempre esteve ao lado dos nossos universitários dispôs a página do jornal "[...] aos nossos universitários para por ela veicularem seus anseios, reivindicações e realizações" (GAZETA DO POVO, $30 \mathrm{dez}$. 1949), inserido o campo da impressa como articuladora entre os campos acadêmicos e políticos, na batalha pela federalização da universidade, assim como já visto na campanha pela restauração.

Essa posição articuladora pode ser observada no jornal Diário da Tarde. Em matéria intitulada Uma campanha necessária e oportuna o periódico referenciou que o reitor da Universidade "[...] em plena e empolgante assembleia universitária, comemorativa de nossa emancipação política, lançou uma causa simpática e emocionante: a da Federalização da nossa gloriosa Universidade" (DIÁRIO DA TARDE, 28 dez. 1949).

Em matéria intitulada Campanha da federalização da Universidade (GAZETA DO POVO, 27 dez. 1949), assinada pelo jornalista paranaense e professor da Faculdade de Direito, Raul Rodrigues Gomes, criticou-se "[...] a exclusão de nossa Universidade do projeto de federalização de todas as instituições de ensino superior do Brasil”. Segundo ele, “[...] estendeu-se essa medida de Estados poderosos como os de São Paulo, Minas, Rio Grande, Pernambuco e Bahia, e as modestas unidades com as do Amazonas, Piauí, Goiás, Ceara, Alagoas sob o pretexto da uniformização de suas diretrizes". Com isso, Raul Gomes, na edição de 6 de janeiro de 1950, lançou na Gazeta do Povo Um inquérito sobre a federalização da universidade.

A imprensa paranaense cobriu a campanha pela federalização da Universidade desde o início até o final. Estabeleceu uma relação entre quatro esferas sociais: professores, estudantes, jornalistas e políticos do Paraná. Nessa relação, percebe-se uma fronteira viva entre o campo político, campo acadêmico e o campo da imprensa. A função do campo da imprensa deu-se no sentido de articular e ao mesmo tempo unificar a luta em torno da federalização. Desse modo, uma campanha lançada pelo reitor Flávio Suplicy ganhou a opinião pública nos jornais, especialmente na Gazeta do Povo, ao lançar um inquérito sobre a federalização. Dessa campanha, evidencia-se significativa notoriedade e reconhecimento a Flávio Suplicy que extrapolou o ambiente universitário e refletiu no cam- 
po acadêmico em uma significativa dominação no campo do poder. No entendimento de Bourdieu (2011, p. 51), “[...] dar ao indivíduo ou a um grupo o nome que ele dá (O Imperador, a nobreza), é reconhecê-lo, aceitá-lo como dominante, admitir seu ponto de vista, aceitar em tomar dele o ponto de vista de perfeita coincidência que ele toma sobre si mesmo". Por outro lado, "[...] também dar outro nome, o nome que lhe dão os outros e principalmente seus inimigos e que ele recusa como insulto, calúnia, difamação (O Usurpador)" (BOURDIEU, 2011, p. 51). Nessas condições, para Bourdieu, o nome tem força no sentido de valor, visibilidade, poder. Esse poder de reconhecimento pode ser positivo (um reitor empreendedor) ou negativo (autoritário, inconsequente, manipulador). Aos olhos do Conselho e da imprensa paranaense, parece que "reitor" no melhor sentido do termo foi o que prevaleceu.

Flávio Suplicy possuía capital cultural herdado e acumulado, um incipiente capital político, mas, sobretudo, um considerável capital social, que lhe deram condições de acumular, no interior do campo universitário, funções de poder na esfera do poder político/acadêmico que lhe deram reconhecimento e permitiram dominar esse campo por sucessivas administrações. Foi o que percebemos na campanha pela federalização. Flávio Suplicy unindo-se a políticos, jornalistas e docentes da Universidade em torno da causa da federalização. Essas estratégias em torno do objetivo a serem alcançados garantiram a ele prestígio e reconhecimento que consubstanciam em domínio no campo do poder universitário. Dotados de diferentes capitais, atuando do interior de um espaço (acadêmico) ou do espaço político propriamente, há uma interface entre as instituições governamentais e o pensamento intelectual. Na Universidade do Paraná, a fronteira entre esses dois campos, desde o início, foi bem estreita, com a prevalência em um primeiro momento do campo político em relação ao campo acadêmico, relativizando-se posteriormente, sobretudo na década de 1940, quando grande parte dos políticos paranaenses eram professores da Universidade.

Na campanha pela restauração, observa-se uma aproximação entre o campo político e o campo acadêmico, chegando, muitas vezes, a confundirem-se os dois espaços sociais. Essa relação pode ser observada na 
imprensa paranaense, onde os nomes de Brasil Pinheiro Machado (Interventor no momento da restauração), Erasto Gaertner e Bento Munhoz da Rocha (deputados), Flávio Suplicy de Lacerda e Homero de Barros (Secretários de Estado) são expressões dessa situação. Esses políticosdocentes uniram-se aos demais professores para debater o assunto com autoridades nacionais, a exemplo dos Ministros Souza Campos, Clemente Mariani e do Presidente Eurico Gaspar Dutra. Com a concretização da restauração da Universidade, em 1946, a imprensa paranaense destacou Brasil Pinheiro Machado, em torno do qual se centralizaram as ações políticas do processo de restauração. Quanto a Flávio Suplicy, ficou clara sua participação como autoridade que conhecia a causa universitária, e por mais que não tivesse envolvimento direto na campanha, esteve entre as autoridades que participaram da solenidade de restauração. Foi em torno desses nomes que se constituiu o poder universitário no período pós-restauração cuja campanha pela federalização foi lançada por Flávio Suplicy de Lacerda e ganhou destaque significativo na imprensa paranaense. A teoria de Bourdieu, sobretudo a partir do conceito de campo, permite entender as relações que se estabelecem do campo da imprensa, com outras esferas, a saber o campo político e campo acadêmico, que vai definindo a tomada de posições e ao mesmo caracteriza a atuação dos intelectuais nos diferentes espaços.

\section{Michel Foucault: do poder sobre o corpo ao poder simbólico}

Em 2002, utilizando como fonte as revistas Veja, Época e IstoÉ, analisamos a presença dos carismáticos católicos e evangélicos pentecostais nos meios de comunicação. No discurso das revistas, apoiando-se nos meios de comunicação e praticando um ritual cúltico semelhante ao dos evangélicos pentecostais os carismáticos procuraram dar visibilidade à Igreja Católica, que nos discursos das revistas, o culto tradicional católico havia sido superado pelos novos cultos dos pentecostais. Nesse sentido, o padre Marcelo Rossi foi apresentado, entre os líderes carismáti- 
cos, como uma figura singular. Ídolo de TV e popstar popular, ele transforma suas missas em grande "espetáculo". Acompanhado de padres cantores (do movimento) e de ídolos populares (profanos) o discurso da mídia enfatiza explicitamente: "A missa do Padre-Show" (VEJA, 10/11/99, p. 172). Ou seja, os discursos das revistas passaram a dar destaque a presença dos padres como decisivo na renovação do catolicismo considerado como tradicional.

Procurando entender o discurso da mídia relacionado aos espetáculos, recorremos ao trabalho de Michel Foucault. Embora não discuta especificamente a natureza da mídia nas sociedades modernas, em Vigiar e Punir, ele argumenta sobre a organização do poder nessas sociedades. Segundo Foucault as sociedades do mundo antigo eram sociedades de espetáculos: o exercício do poder estava ligado à manifestação pública de força e superioridade do soberano. Era um regime de poder no qual uns poucos tornavam visíveis a muitos, e no qual a visibilidade de poucos era usada para exercer o poder sobre muitos - de tal maneira, por exemplo, que a execução numa praça pública se tornava um espetáculo:

[...] há também alguma coisa de desafio e de justa na cerimônia de suplício. Se o carrasco triunfa, se consegue fazer saltar com um golpe a cabeça que lhe mandaram abater, ele a mostra ao povo, põe-na no chão e saúda em seguida o público que o ovaciona muito, batendo palmas. (FOUCAULT, 1995, p. 48)

Portanto, a presença do público era imprescindível em qualquer suplício que existisse. Com relação a isso, Foucault (1995, p. 53) faz um novo comentário:

Nas cerimônias do suplício, o personagem principal é o povo, cuja presença real e imediata é requerida para sua utilização. Um suplício que tivesse sido conhecido, mas cujo desenrolar houvesse sido secreto não teria sentido. Procurava-se dar o exemplo não só suscitando a consciência de que a menor infração corria sério risco de punição; mas provocando um efeito de terror pelo espetáculo do poder tripudiante sobre o culpado: em material criminal, o ponto mais difícil é a imposição da pena: e o objetivo é o fim do processo, e o único fruto, pelo exemplo e pelo terror, quando é bem aplicado ao culpado. 
Nesta análise se dá relevada importância aos rituais. Esses rituais desempenhavam um papel significativo na coroação de reis, transferências de terras e suplícios. Mas a partir do século XVI a manifestação espetacular do poder cedeu lugar a novas formas de disciplina e controle que foram se infiltrando nas diferentes esferas da vida. O exército, a escola, a prisão, o hospital, empregaram de forma crescente os mecanismos mais sutis de poder baseados no treinamento, na disciplina, na observação e no registro. A propagação destes mecanismos gradualmente fez surgir um novo tipo de "sociedade disciplinar" em que a visibilidade de poucos diante de muitos foi substituída pela visibilidade de muitos diante de poucos, e na qual a manifestação espetacular do poder soberano foi substituída pelo poder do olhar. Como exemplo podemos citar a televisão, onde uma única pessoa assiste a multidões.

Peter Burke (2006, p. 19) afirma que "a palavra 'espetáculo', comumente usada no século XVII, foi ressuscitada no século XX”. Os rituais eram mensagens, mais também um meio mais ou menos eficaz de comunicar informação. Isso porque a condição de assimilação poderia ser aceita pela maioria ou minoria do publico presente. No entanto o autor ainda continua:

Os estudiosos franceses entraram no tema por diversas vezes: três deles, conscientes de que estavam escrevendo de dentro de uma sociedade eletrônica eram Guy Debord, Jean Baudrillard e Pierre Bourdieu. A obra $A$ sociedade do espetáculo (1970), de Debord, tradução de um manifesto em francês e publicada em 1967 com poucas evidências empíricas, argumentava que em sociedades nas quais "prevalecem às modernas condições de produção toda a vida se representa como uma imensa acumulação de espetáculos. Tudo que era vivido diretamente mudou-se para uma representação". Portanto, o espetáculo tornou-se o mundo. Deve-se contrastar essa observação como o modesto comentário do escritor norte americanos de televisão Richard Adler: "a tela pequena limita gravemente a eficácia do espetáculo”. (BURKE, 2006, p. 249).

Nos meios de comunicação tempo e espaço são derribadas e ideologias passam a ser socializadas de forma rápida e barata. $\mathrm{O}$ eu e você (a interação - face-a-face e pessoal), passa a ser mediada pela ampla e cres- 
cente, instituições e meios de "comunicação de massa". Thompson, (1998, p. 25) diz que: "é interação, porque, ela envolve indivíduos se comunicando com outros, que responde a eles de certo modo e que podem criar laços às vezes intenso - de amizade, afeição e lealdade. Mas é uma quase interação, porque o fluxo de comunicação é predominantemente em mão única e os modos de respostas possíveis aos receptores são estritamente limitados (THOMPSON, 1998, p. 27).

Nessa relação surge um novo tipo de poder: o poder simbólico. $\mathrm{Ou}$ seja, aquele poder que tinha necessidade de ficar marcado no corpo e com a presença do publico (efeito medo), passa a ser substituído pelo poder sobre a mente. Para Thompson (1998, p. 24):

\begin{abstract}
Se a atividade simbólica é uma característica penetrante da vida social, há entretanto, uma grande variedade de instituições que assumem um papel particular historicamente importante na acumulação dos meios de informação e de comunicação. Estas incluem instituições religiosas, que se dedicam a produção e difusão de formas simbólicas associadas a salvação, aos valores espirituais e as crenças transcendentais.
\end{abstract}

Segundo Jürgen Habermas (1984, p. 39), “já desde o último terço do século XVII, os jornais são complementados por revistas, que não contém, em primeira linha, informações, mas instruções pedagógicas, e até mesmo crítica e resenhas”. Thomaz Souto Corrêa (2008) informa que em primeiro lugar as revistas são destinadas ao grande público e são vendidas nas bancas e por assinaturas. Em um segundo momento elas são destinadas ao público mais especifico ou grupos restritos de profissionais, ou seja, revistas cientificas e com conteúdos específicos. Em nosso estudo tivemos como objeto os conteúdos das revistas de consumo. Com relação a revista Veja, foi fundada em 1968 pelo grupo Abril sob a coordenação de Victor Civita. Surgida em plena ditadura militar a revista passou por um período intenso de crise até firmar como revista de importante circulação no cenário nacional. Conforme Corrêa,

Aos poucos, Veja foi se tornando cada vez mais importante na vida da nação. Lançada poucas semanas antes do AI-5, Veja sofreu a consequência da censura: em 1969, com uma capa sobre tortura, a revista foi apreendida. Como aconteceu com toda a 
grande imprensa, muitas edições saíram mutiladas pelos cortes dos censores. Mas, quando veio a abertura, a postura combativa - abafada, mas não extinta, na era da censura dos militares voltou com toda a força e passou a dar exemplos de jornalismo investigativo. (CORR $\hat{E A}, 2008$, p. 221-222).

Seu caráter conservador e tendencioso ultimamente tem sido alvo de intelectuais. A revista Veja muitas vezes tem apresentado em seu conteúdo a sociedade brasileira a partir de uma interpretação elitista. A revista IstoÉ, fundada em 1976, por Domingo Alzugaray, da Editora Três, seguiu na mesma linha do jornalismo investigativo acompanhado de sensacionalismo e de comoção da opinião pública. Investindo no mesmo tipo de jornalismo, surgiu em 1998 a revista Época, da Editora Globo. Ao compreendermos a mídia, como primordial na transmissão de formas simbólicas, analisamos do ponto de vista dela, o sensacionalismo usado, nos conteúdos sobre religião e caracterizado como um "Espetáculo".

No discurso da mídia, o padre Marcelo Rossi impulsionou o Movimento Carismático. Numa análise genérica, é consenso entre as revistas pesquisadas que multidões acompanham suas missas nos templos, estádios e pelos meios de comunicação. Essa popularidade alcançada pelo padre Marcelo fez com que os meios de comunicação o apresentassem como um popstar da "Era das Celebridades" (VEJA, 12/01/2000, p. 106). Com relação ao padre Marcelo, o discurso da mídia é enfático. Podemos perceber esta dimensão através da passagem retirada de IstoÉ.

Ele é alto, tem olhos verdes e o corpo malhado pelos anos em que foi professor de ginástica dos bairros nobres de São Paulo: Pinheiros e Itaim. No domingo 2,100 mil pessoas foram ao estádio do Morumbi para vê-lo. Apenas 70 mil conseguiram entrar, seguindo os passos de outras 45 mil pessoas que há apenas dois meses, lotaram o ginásio da Portuguesa de Desportos. Aos 30 anos, Marcelo Rossi atrai multidões não pelos seus dotes físicos, mas por suas palavras de fé. Ordenado há apenas três anos, padre Marcelo é hoje o maior fenômeno da igreja católica em São Paulo. Além de lotar estádios, ele mantém um programa de rádio, campeão de audiência no seu horário é um do melhores Ibopes da Rede Vida, a emissora católica que alcança 17 Estados do país. (ISTOÉ, 12/11/97, p. 43). 
O discurso da mídia faz um apelo abusivo a beleza do padre Marcelo. Depois suaviza, dizendo que o fator preponderante são suas palavras de fé. O mais significativo, é a participação de fiéis, cuja revista transforma em números, e pode ser aproximado dos fãs de futebol e artistas, que têm suas apresentações disputadas por multidões. Ainda em relação ao padre Marcelo o discurso apresenta como possível imitador dos cultos pentecostais:

Apoiado pelos conservadores e criticado pelos progressistas, padre Marcelo é um dos expoentes de Renovação Carismática, que adota, na igreja católica, as mesmas técnicas dos pentecostais. Duas vezes por semana, às quintas e sábados, padre Marcelo reúne em suas missas na Igreja do Perpétuo Socorro, no bairro de Santo Amaro, uma multidão de fiéis. Nessas horas seus seguidores rezam com fervor, seguram terços nas mãos, batem palmas e gesticulam, embalados por hinos católicos. (ISTOÉ, 12/11/97, p. 43).

Quando o padre Marcelo entra no altar, a formalidade cúltica se transforma num evento distinto da prática religiosa convencional. Cada celebração é um megaespetáculo (VEJA, 04/11/98, p. 115). Diante da multidão o padre Marcelo é o Rei da homilia. Canta, dança, prega de forma didática. Abusa das parábolas e dos diálogos com a plateia. Nada que lembre o estágio monódico das missas tradicionais.

O Movimento Carismático pode ser considerado como um dos responsáveis por essa inovação. Tendo como principal personagem, o padre Marcelo Rossi, "O Fenômeno da Mídia”, a Igreja Católica tem conseguido atrair multidões. Essa nova fase religiosa, marcada intensamente pelos meios de comunicação, que discursam de forma sensacionalista a imagem do padre Marcelo, se configuram como um estímulo, para que jovens padres trilhem, rumo a fama, e apelem para a mídia, que dá uma nova dinâmica a religiosidade.

Além do padre Marcelo, outros padres, a exemplo do padre Zézinho, Antônio Maria, padre Zeca são apresentados pelas revistas. No discurso das revistas pesquisadas a igreja católica parece ter encontrado na ação dos padres cantores uma forma de se contrapor ao avanço evangélico. Os padres cantores se configuram como uma peça importante no for- 
talecimento do Movimento Carismático. Já são inúmeros os padres que cantam e dançam para louvar ao Senhor. Essas missas estilo Shows são apresentadas pela mídia como "espetáculos".

Em Foucault, quando ele analisa a transmissão dos suplícios para a privação da liberdade nas prisões, percebemos que existe uma diferença entre a sociedade do antigo Regime e a sociedade atual. Aquela era uma sociedade de "Espetáculo" onde as pessoas se reuniam nas praças públicas para assistir as comoventes cenas torturantes praticadas nos suplícios. Foucault não analisa a mídia especificamente, nem o espetáculo que descreve se identifica com o espetáculo da religião ao qual abordamos. Mas o que nos importa na sua análise é a transitoriedade das manifestações espetaculares. Naquela época exigia-se a presença do público que além de aplaudir as cenas, estendiam as demais pessoas a dimensão do acontecimento. Hoje os espetáculos continuam exigindo a presença do público. Mas a presença deles é para dar prestígio e notoriedade aos artistas, cantores, jogadores. Por outro lado, a imprensa e a mídia, de forma geral, estampam em suas páginas as multidões que acompanham os shows. Portanto não se trata de uma forma de repressão, mas sim, de prestígio do artista e que a mídia tem um papel fundamental na criação das celebridades.

No discurso da mídia, inspirados nos televangelistas pentecostais americanos, Edir Macedo e David Miranda revolucionaram a religião de mídia brasileira apoderando-se desses meios de comunicação. Nesse discurso todo, em que situação a igreja católica iria ficar? A mídia se preocuparia exclusivamente em discursar a multinacionalização da igreja do Bispo Macedo? Sem sombras de dúvida que não. Para impulsionar a competividade no cenário brasileiro, a mídia encontra outro objeto discursivo: "com missas de cura e usando a mídia, os carismáticos lotam os templos e mudam o perfil da igreja católica” (ISTOÉ, 24/12/97, p. 95). Esta mudança do perfil católico não estava só ela impulsionada pelo movimento carismático, surgido na década de 6o. É exatamente nesse momento que a mídia atua como uma fábrica de celebridades e coloca uma estrela no altar: "Jovem, bonito e carismático, o padre Marcelo atrai multidões e renova a igreja católica no país” (VEJA, 04/11/1998, p. 114). A 
partir desse momento o discurso religioso da mídia evoca a noção do espetáculo da religião.

Com os apontamentos teóricos de Foucault, procuramos entender a noção desse espetáculo. Embora não trabalhe especificamente com a mídia, o autor nos convida para percepção da mudança de visibilidade. Segundo ele, a presença do público era exigida para testemunhar as cenas torturantes. Hoje o rádio, a televisão, o livro, as revistas, estendem até o público a relevância dos acontecimentos. Ela cria, no lugar do poder soberano, abordado por Foucault, o poder simbólico, que conforme a definição de Thompson (1998, p. 17), tem a capacidade para "intervir nos cursos dos acontecimentos, influenciar as ações e de fato, criar fatos por meio da produção e transmissão das formas simbólicas”. Com isso concluímos que o "Espetáculo da Religião" está presente nos discursos das revistas pesquisadas e com os apontamentos teóricos de Foucault foi possível entender que transformam o culto religioso em ato surreal atraindo milhões de pessoas para acompanhar a missa dos padres.

\section{Considerações finais}

A mídia de modo geral e particularmente a imprensa, faz parte integrante da realidade, ou mais precisamente, produz efeitos da realidade, criando uma visão midiática, que contribui para descrever uma realidade que muitas vezes vai além do real. A lógica dos jornalistas é estabelecer relações que se instaurem entre os atores sociais, no sentido de provocar ou promover a chamada opinião publica. Neste sentido o objetivo principal deste texto foi apresentar, mediante várias pesquisas, a utilização das fontes impressas para história e particularmente para a história da educação. Nesta direção buscamos operar empiricamente, um conjunto de fontes (jornais e revistas), que abrangem com algumas interrupções o longo século XX. Com isso, nossa intenção foi lançar os fundamentos teóricos de autores que tem mobilizado nossas pesquisas e ao mesmo tempo, lançar de forma introdutória os efeitos práticos da utilização da imprensa como fonte de pesquisa. 
Este tipo de abordagem possibilitou situar a imprensa periódica como fonte para pesquisas, demonstrando, numa tentativa empírica a grande relevância da imprensa como fonte única ou complementar, evidenciando a importância da imprensa no debate educacional e particularmente no estudo da história recente. Ao apontar os debates promovidos no espaço da imprensa, foi possível evidenciar o papel dos intelectuais, cujos discursos apontam as transformações e lutas por essas transformações.

Das nossas pesquisas, evidenciamos que a imprensa, a partir dos questionamentos do pesquisador, evidencia as questões presentes nos vários momentos históricos, bem como testemunha as transformações que a educação assume nos mais diferentes contextos. Isso porque, na sua função integradora, a imprensa de modo geral trás para discussão a opinião e a presença de intelectuais que representam vários campos. Esse papel articulador, conforme explicita Bourdieu, justifica por si só o uso da imprensa como fonte para pesquisa em história e história da educação. Mais do que isso, no momento histórico, onde percebemos a atuação da imprensa, na dimensão não apenas política e ideológica é necessário o continuo esforço de pesquisadores para fazer leitura das linguagens, apropriações e analise das varias tendências por eles abordados e que se tornam a cada dia, o trato das pesquisas com jornais, mais cuidadosas, complexas e reveladoras do debate intelectual nas amplas dimensões que a imprensa oferece aos diferentes públicos.

Com base nessas pesquisas percebemos algumas características no que se refere as fontes imprensas para pesquisas em educação e história. Com relação aos jornais encontramos vários obstáculos. O principal deles foi a péssima condição de preservação dos jornais. Além de muitos números não terem sido arquivados, boa parte do material encontra-se fechado para pesquisa. Nos tempos mais recentes, era das grandes revistas, e dos grandes jornais, temos várias vantagens, principalmente se compararmos com as fontes mais antigas. Estas além de estarem espalhadas em vários espaços públicos, como boa preservação, contam com arquivos digitalizados que podem ser acessadas pela internet. Ou seja, podemos encontrar um montante significativo de material a ser pesquisado, que deve 
contar com um trabalho de seleção por parte do pesquisador, devido ao grande montante de materiais preservados.

Devido a amplitude temática abordada pelos periódicos é possível pesquisar não só a educação, mas enfim, comportamentos, politicas, tecnologia, modernidade, etc. Diante desses apontamentos reafirmamos o dialogo com Gramsci, Bourdieu e Foucault na analise das fontes impressas, não só para estudar o papel dos intelectuais nos vários espaços, mas sobretudo, para entender as relações de poder, caracterizada particularmente pelo poder simbólico, na atuação da imprensa e mídia em geral.

\section{Referências}

BAKHTIN, M. V. Marxismo e filosofia da linguagem: problemas fundamentais do método sociológico na ciência da linguagem. São Paulo: Ed. Annablume, 2002.

BOURDIEU, P. O poder simbólico. Rio de Janeiro: Ed. Bertrand Brasil, 1998.

. Sobre a televisão: seguido de a influência do jornalismo e os jogos olímpicos. Rio de Janeiro: Jorge Zahar Editor, 1997.

. Algumas propriedades dos campos. In: Questões de Sociologia.

Lisboa: Fim de Século, 2003, p. 119-126.

. Homo Academicus. Florianópolis: UFSC, 2011a.

BUCHOLDZ, A. P. Diário dos Campos: memórias de um jornal centenário. Ponta Grossa: Editora UEPG, 2007.

BURKE, P; BRIGGS, A. Uma história social da mídia: de Gutenberg à internet. Rio de janeiro: Zahar, 2006.

CAMPOS, N. Discurso: Lugar de Produção de sentidos e de luta pela verdade. Revista Publicatio, v. 15, n. 2, p. 129-138, 2007.

CAPELATO, M. H.; PRADO, M. L. O bravo matutino: imprensa e ideologia: o jornal $O$ Estado de S. Paulo. São Paulo: Alfa-Omega, 1980.

ELUTÉRIO, M. L. Imprensa a serviço do progresso. In: MARTINS, A. L.; LUCA, T. R. (org.) História da imprensa no Brasil. São Paulo: Contexto, 2008. 
FOUCAULT, M. Vigiar e punir: história da violência nas prisões. Rio de Janeiro: Ed. Petrópolis, 1983.

GRAMSCI, A. Cadernos do cárcere. Vol. 2. Rio de Janeiro: Civilização Brasileira, 2006.

HABERMAS, J. Mudança estrutural na esfera pública. Rio de Janeiro: Tempo Brasileiro, 1984.

LUCA, T. R. História dos, nos e por meio dos periódicos. In: PINSKY, C. B. (org.). Fontes Históricas. São Paulo: Contexto, 2005. p. 111-153.

MARTINS, A. L.; LUCA, T. R. (org.) História da imprensa no Brasil. São Paulo: Contexto 2008.

SOUZA, E. F. Intelectuais, Modernidade e discurso Educativo no jornal. Dissertação de mestrado (Educação). Universidade Estadual de Ponta Grossa, Ponta Grossa, 2010.

THOMPSON, J. B. A mídia e a modernidade. Rio de Janeiro: Ed. Vozes - Petrópolis, 1998.

VEIGA, C. G. História da Educação. São Paulo: Ática, 2007.

VIEIRA, C. E. Jornal diário como fonte e como tema para a pesquisa em história da Educação: um estudo da relação entre imprensa, intelectuais e modernidade nos anos de 1920. In: OLIVEIRA, M. T. Cinco estudos em história e historiografia da Educação. Belo Horizonte: Autêntica Editora, 2007, p. 11-40. 